\title{
Assessment of a High-Resolution Climate Model for Surface Water and Energy Flux Simulations over Global Land: An Intercomparison with Reanalyses
}

\author{
DI TIAN \\ Department of Crop, Soil, and Environmental Sciences, Auburn University, Auburn, Alabama \\ MING PAN AND ERIC F. WOOD \\ Department of Civil and Environmental Engineering, Princeton University, Princeton, New Jersey
}

(Manuscript received 17 August 2017, in final form 19 April 2018)

\begin{abstract}
Land surface water and energy fluxes from the ensemble mean of the Atmospheric Model Intercomparison Project (AMIP) simulations of a Geophysical Fluid Dynamics Laboratory (GFDL) high-resolution climate model (AM2.5) were evaluated using offline simulations of a calibrated land surface model [Princeton Global Forcing (PGF)/VIC] and intercompared with three reanalysis datasets: MERRA-Land, ERA-Interim/Land, and CFSR. Using PGF/VIC as the reference, the AM2.5 precipitation, evapotranspiration, and runoff showed a global positive bias of $\sim 0.44, \sim 0.27$, and $\sim 0.15 \mathrm{~mm} \mathrm{day}^{-1}$, respectively. For the energy budget, while the AM2.5 net radiation agreed very well with the PGF/VIC, the AM2.5 improperly partitioned the net radiation, with the latent heat showing positive bias and sensible heat showing negative bias. The AM2.5 net radiation, latent heat, and sensible heat relative to the $\mathrm{PGF} / \mathrm{VIC}$ had a global negative bias of $\sim 1.42 \mathrm{~W} \mathrm{~m}^{-2}$, positive bias of $\sim 7.8 \mathrm{~W} \mathrm{~m}^{-2}$, and negative bias of $\sim 8.7 \mathrm{~W} \mathrm{~m}^{-2}$, respectively. The three reanalyses show greater biases in net radiation, likely due to the deficiencies in cloud parameterizations. At a regional scale, the biases of the AM2.5 water and energy budget components are mostly comparable to the three reanalyses and PGF/VIC. While the AM2.5 well simulated the actual values of water and energy fluxes, the temporal anomaly correlations of the three reanalyses with PGF/VIC were mostly greater than the AM2.5, partly due to the ensemble mean of the AM2.5 members averaging out the intrinsic variability of the land surface fluxes. The discrepancies among land surface model simulations, reanalyses, and high-resolution climate model simulations demonstrate the challenges in estimating and evaluating land surface hydrologic fluxes at regional-to-global scales.
\end{abstract}

\section{Introduction}

A primary goal of the World Climate Research Programme's (WCRP) Global Energy and Water Exchanges (GEWEX) project is to improve coupled model predictions through evaluation of climate models' water and energy budgets using regional-to-continental datasets. The quality of a climate model simulation, including land surface hydrologic fluxes, depends upon how the physical processes are represented, how accurately the model parameterizations are characterized, and the availability and quality of forcing data. The Atmospheric Model Intercomparison Project (AMIP) provides a community-based framework for climate model diagnosis, validation, intercomparison, documentation, and data access. However, few studies have

Corresponding author: Di Tian, tiandi@auburn.edu been conducted to characterize systematic errors in land surface hydrology fluxes present in any AMIP experiment.

The National Oceanic and Atmospheric Administration (NOAA) Geophysical Fluid Dynamic Laboratory (GFDL) Atmospheric Model (AM2.5) AMIP simulations were developed by coupling land and atmospheric components of the CM2.5 model (Delworth et al. 2012) with forcing from observation-based sea surface temperature (SST) and sea ice. Assessing AM2.5 AMIP simulations for land surface water and energy budgets will be helpful for identifying model deficiencies, which is necessary for further improvement of AM2.5 simulations. In addition, the simulations of the AM2.5 were used as initial conditions for a Forecast-Oriented Low Ocean Resolution version (FLOR) of the GFDL model. The GFDL FLOR was regarded as the first highresolution climate model used for operational seasonal 
forecasting in the United States (Jia et al. 2015). Since climate model predictions are largely affected by the accuracy of initial atmospheric and land states (e.g., Materia et al. 2014; Jia et al. 2016), quantifying errors in the water and energy budgets from initial states of climate forecast models is necessary for improving the predictive skill from daily to seasonal time scales.

Global meteorological reanalysis datasets are produced by assimilating in situ and satellite-based observations into the forecast model. Reanalysis data provides multiple climate variables with complete and coherent spatial coverage over the globe, which have been increasingly used as a surrogate for observations, particularly over data-sparse regions. There are several recent reanalysis datasets developed by major climate centers, such as the National Centers for Environmental Prediction (NCEP) Climate Forecast System Reanalysis (CFSR; Saha et al. 2010), NASA Modern-Era Retrospective Analysis for Research and Application (MERRA; Rienecker et al. 2011), and European Centre for MediumRange Weather Forecasts (ECMWF) interim reanalysis (ERA-Interim; Dee et al. 2011). Among the reanalyses, improved sets of land surface hydrological fields are generated by rerunning a revised version of the land component of the MERRA system (MERRA-Land; Rienecker et al. 2011) and the ERA-Interim system (ERA-Interim/ Land, here shortened to ERA-I/Land; Balsamo et al. 2015). The MERRA-Land and ERA-I/Land datasets appeared more accurate than their original reanalyses, and both are recommended for land surface hydrological studies (Reichle et al. 2011).

Many studies have focused on assessing land surface water and energy budget components of atmospheric models and reanalyses at large basin scales, such as the Amazon, Mackenzie, and Mississippi (e.g., Betts et al. 2009; Fernandes et al. 2008; Szeto 2007; Yang et al. 2015). However, few studies evaluate them at continental-to-global scales. The Princeton Global Forcing (PGF) data (Sheffield et al. 2006) as well as the well-calibrated Variable Infiltration Capacity (VIC) model simulations forced by the PGF (PGF/VIC; Sheffield and Wood 2007; Pan et al. 2012) provide reliable information about climatology and the variability of global water and energy budgets. In a previous study, we assessed the AM2.5 land surface water and energy budgets using the PGF/VIC at the river basin scale over Africa (Tian et al. 2016). The results show that, over African river basins, the AM2.5 mostly overestimates precipitation, evapotranspiration, and runoff relative to PGF/VIC and reanalyses; for the energy budget, the AM2.5 shows consistent solar radiation but lower sensible heat and a higher latent heat relative to the other datasets. While this basin-scale assessment provides important information on how well the AM2.5 can simulate surface water and energy budgets in Africa, its land surface hydrology simulations in the other regions of the world have not been evaluated yet. In this paper, we further examine how well the AM2.5 land surface water and energy budget variables over land agree with the PGF/VIC data relative to MERRA-Land, ERA-I/ Land, and CFSR reanalysis datasets over the globe. This assessment will be helpful for diagnosing the AM2.5 deficiencies and providing useful information for improving land surface hydrology simulations.

\section{Data and methods}

\section{a. GFDL AM2.5 simulations}

The AMIP simulations of the GFDL AM2.5 have been archived from 1981 to 2010. This model coupled land and atmospheric components of the CM2.5 model (Delworth et al. 2012) and was forced by observationbased SST and sea ice. The AM2.5 AMIP simulations archived 12-member ensembles of monthly mean daily variables at a spatial resolution of $0.5^{\circ} \times 0.5^{\circ}$ (approximately $50 \mathrm{~km} \times 50 \mathrm{~km}$ ) across the globe. To capture the average large-scale seasonal and regional features of land surface hydrologic fluxes, the 12-member ensembles from the AM2.5 were averaged into one ensemble mean. The monthly mean of daily water and energy budget variables over the 20-yr period from 1991 to 2010 was then evaluated, including precipitation $P$, evapotranspiration $(\mathrm{ET})$, runoff $(\mathrm{RO})$, net radiation $(\mathrm{Rn})$, latent heat $(\mathrm{LH})$, and sensible heat $(\mathrm{SH})$. For the regional evaluation, the gridded data were averaged over each of the world regions defined by Giorgi and Francisco (2000), as shown in Fig. 1.

\section{b. Reanalysis products}

The AMIP simulations of the AM2.5 water and energy budget variables are intercompared with three global reanalysis datasets: MERRA-Land, ERA-I/Land, and CFSR as well as the PGF/VIC reference data. It is worth noting that, while the reanalyses and PGF/VIC data are generated at resolutions of $1^{\circ}$ or less, the observed information content (especially precipitation) used in these datasets can be much coarser, particularly in data-sparse regions such as the tropics. The MERRA-Land, ERA-I/Land, and CFSR datasets archived monthly mean daily data from 1979 to present. The native resolution in space for the datasets is approximately $0.5^{\circ} \times 0.5^{\circ}$ for CFSR, $0.5^{\circ} \times 0.7^{\circ}$ for MERRA-Land, and $0.8^{\circ}$ for ERA-I/Land. For comparison, all three datasets were regridded (using bilinear interpolation) to the resolution of the AM2.5 data $\left(0.5^{\circ} \times 0.5^{\circ}\right)$. Since all variables are on monthly mean 


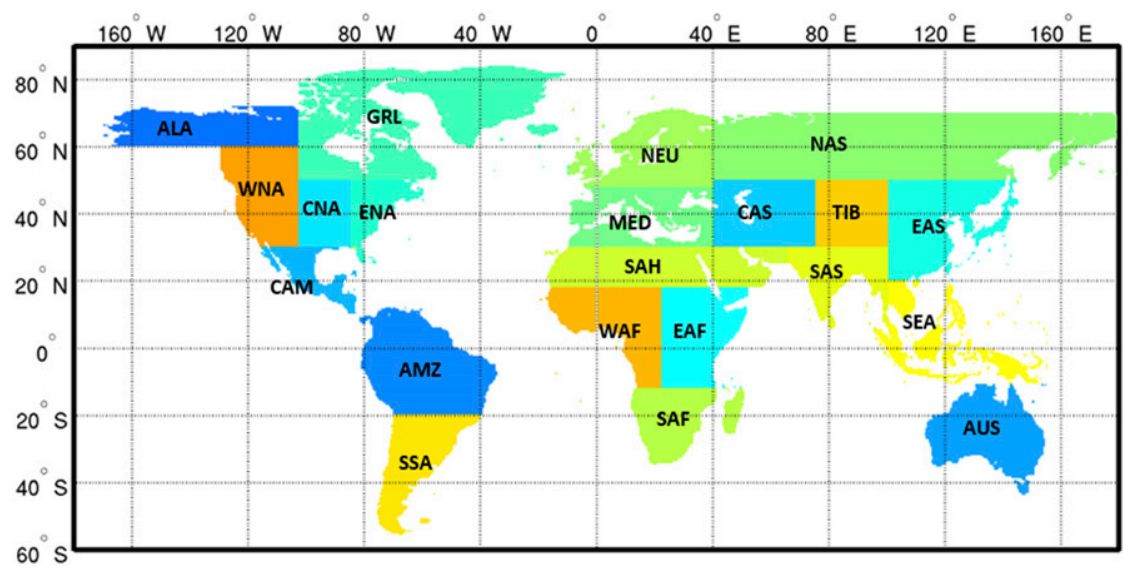

FIG. 1. Map of regions used for the analysis as defined by Giorgi and Francisco (2000).

time scales, which are reasonably smooth in space, it is adequate to use bilinear interpolation for gridding the datasets. The NCEP CFSR is the first global reanalysis data developed based on a coupled land-atmosphereocean-sea ice system. Saha et al. (2010) described the CFSR product in detail. In general, the CFSR land surface analysis assimilated satellite radiances and hydrological quantities from the four-layered Noah land surface model (Ek et al. 2003). It updated the Noah land surface model using the Climate Prediction Center (CPC) merged analysis of precipitation (Xie and Arkin 1997) and the CPC unified daily gauge analysis (Xie et al. 2010) in place of the atmospheric model's guess forecasts. The NASA MERRA-Land showed improved representations of hydrological cycles in global assessments (Rienecker et al. 2011). MERRA-Land was developed from MERRA, which was based on the NASA's Goddard Earth Observing System version 5 (GEOS-5) global climate model system (Rienecker et al. 2008) and a catchment hydrological model (Koster et al. 2000). MERRA-Land was generated by rerunning the revised version land component of the GEOS-5 model with updated rainfall interception parameters and the precipitation forcing corrected by the Global Precipitation Climatology Project (GPCP) product. The MERRA-Land data showed better accuracy than the original MERRA estimates and was recommended for land surface hydrological studies (Reichle et al. 2011). ERA-I/Land was developed based on ERA-Interim, which was produced by ECMWF with a sequential fourdimensional variational data assimilation scheme using the forecast model and observations (Dee et al. 2011). The forecast model used by ERA-Interim was the ECMWF Integrated Forecast System (IFS), which fully coupled three components for the atmosphere, land surface, and ocean. ERA-I/Land includes parameterization improvements in the land surface scheme with respect to the original ERA-Interim dataset as well as bias correction of precipitation forcing. It shows better performance than ERA-Interim in terms of land surface hydrological simulations and is considered more suitable than the original ERA-Interim for climate studies involving land water resources (Balsamo et al. 2015).

\section{c. PGF/VIC simulations}

The reference dataset is from the VIC model simulations of Pan et al. (2012) forced by the PGF data (Sheffield et al. 2006). The forcing dataset and the simulation have been updated using the latest versions of the Climatic Research Unit (CRU) monthly temperature and precipitation datasets and the Surface Radiation Budget (SRB) monthly downward short- and longwave radiation product. The model parameters have also been updated via calibration based on spatially disaggregated streamflow observations (Sheffield et al. 2009) using the sparse-grid calibration strategy of Troy et al. (2008). The model simulations agreed well with observations for both water budgets (Pan et al. 2012; Vinukollu et al. 2012; Sheffield and Wood 2007) and energy budgets (Vinukollu et al. 2012). The VIC global monthly streamflow simulation showed that the Nash-Sutcliffe efficiency coefficients mostly vary between 0.6 and 0.9 for the calibration period (1952-81) and between 0.5 and 0.8 for the validation period (19822006), except for heavily managed basins such as the Yellow and Murray-Darling. PGF precipitation and temperature were produced by scaling the NCEPNCAR reanalysis to match the CRU dataset at a monthly time scale, so the PGF monthly precipitation and temperature are essentially the same as the CRU TS3.0 constructed by merging several station-based observation datasets over global land (Mitchell and 

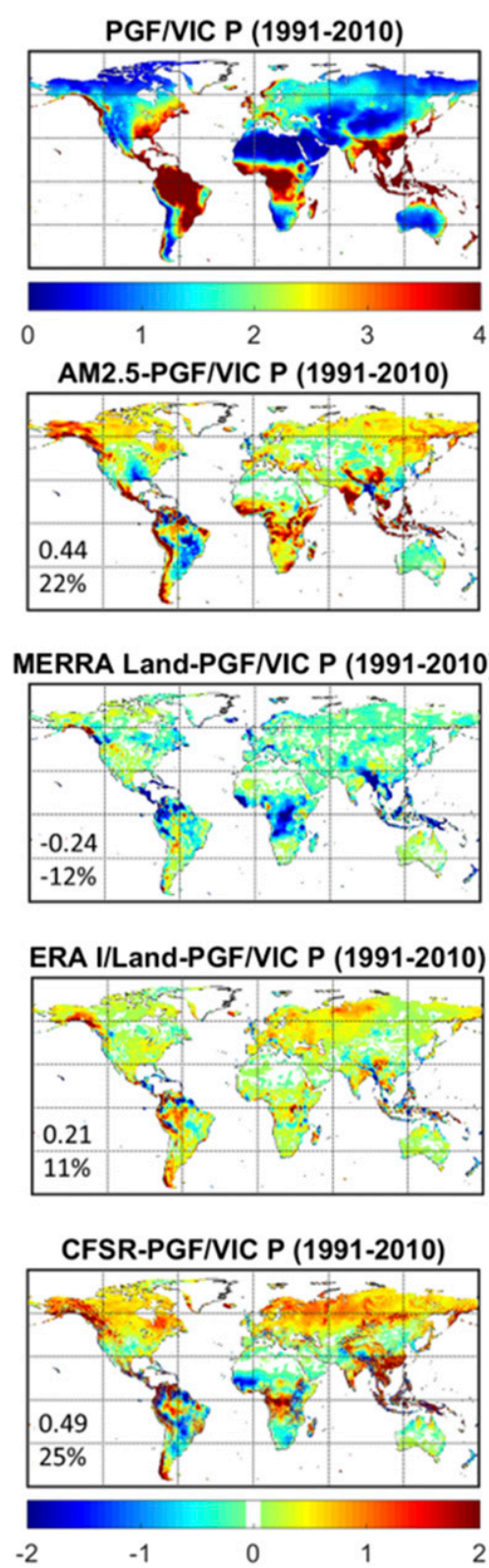
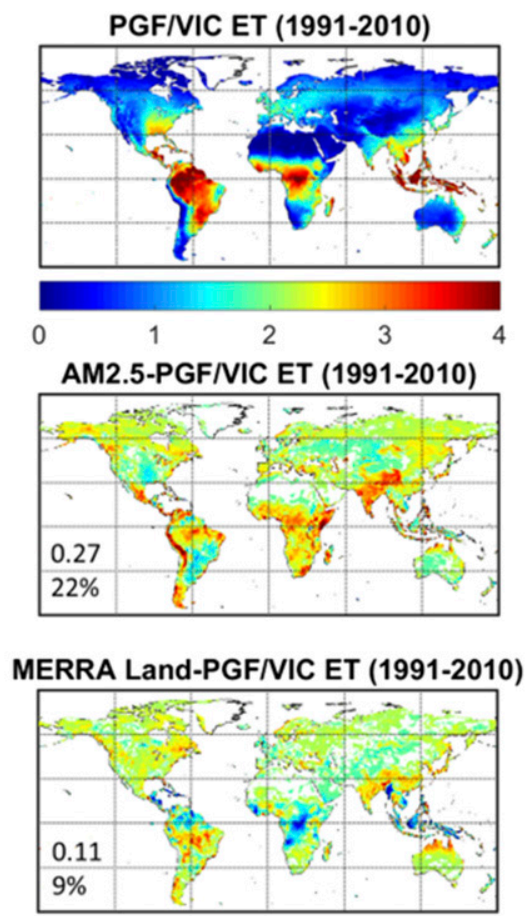

ERA I/Land-PGF/VIC ET (1991-2010)


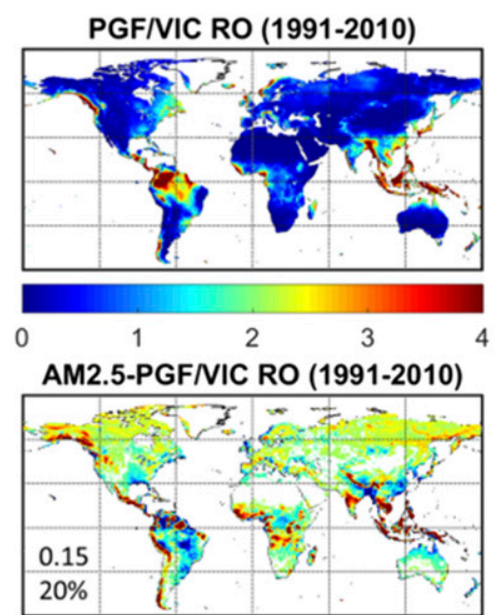

MERRA Land-PGF/VIC RO (1991-2010)

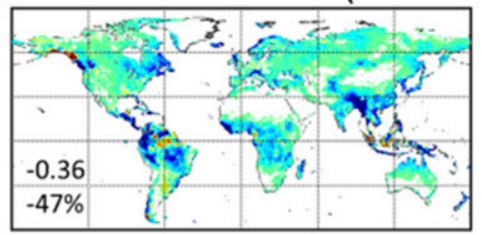

ERA I/Land-PGF/VIC RO (1991-2010)


FIG. 2. (top) The actual values of PGF/VIC; the remaining rows show the difference between each dataset and PGF/VIC for long-term mean water flux $\left(\mathrm{mm} \mathrm{day}^{-1}\right)$ over 1991-2010. The numbers represent the mean difference in actual value (mm day $\left.{ }^{-1}\right)$ and percentage $(\%)$.

Jones 2005; Harris et al. 2014). PGF radiation data after 1984 were produced by scaling the NCEP-NCAR reanalysis to match the NASA/GEWEX SRB satellitebased monthly downward short- and longwave radiation product. While the PGF data are relatively uncertain in data-sparse regions, they arguably provided the most realistic precipitation, temperature, and radiation forcings for the VIC model. Since VIC was forced with observed $P$ and calibrated against observed runoff, and VIC forces water balance by model construct, ET and
RO from PGF/VIC are reasonable estimates of water budgets. Given that, the PGF/VIC radiation forcings are satellite observations and the water budget variables are reasonable estimates, so by inference, the estimates of land surface energy fluxes should be reasonable.

PGF/VIC and the three reanalyses (MERRA-Land, ERA-I/Land, and CFSR) were used to provide complementary information for AM2.5 evaluations. This is because errors may exist regionally in both PGF/VIC and reanalyses due to poor observational data, insufficient 
calibration, and model structural error. However, since these datasets are generated with different models and forcing datasets with notable common features, an intercomparison of AM2.5 with PGF/VIC and the three reanalyses would help us better understand the AM2.5 performance in the context of state-of-art reanalyses and land surface model simulations.

\section{Results and discussion}

\section{a. Global comparisons}

\section{1) WATER FLUXES OVER LAND}

Figure 2 shows global maps of PGF/VIC and the differences between each dataset and PGF/VIC for the longterm mean of precipitation, evapotranspiration, and runoff from 1991 to 2010. The numbers in each of the maps from the second row to the last are the global average differences in actual value and percentage. The AM2.5 precipitation shows a global positive bias of $\sim 0.44 \mathrm{~mm} \mathrm{day}^{-1}(\sim 22 \%$ of long-term mean precipitation) with respect to PGF/VIC. The AM2.5 evapotranspiration has a global positive bias of only $\sim 0.27 \mathrm{~mm} \mathrm{day}^{-1}$ ( $\sim 22 \%$ of long-term mean evapotranspiration) with respect to the PGF/VIC. The global bias of runoff is positive $\sim 0.15 \mathrm{~mm} \mathrm{day}^{-1}$ ( $\sim 20 \%$ of long-term mean runoff) with respect to the PGF/VIC. The spatial performance of the AM2.5 water budget components is different among the three reanalyses. While the long-term mean difference in precipitation and evapotranspiration between AM2.5 and PGF/VIC is larger than the difference between MERRA-Land and PGF/VIC over most areas, for runoff values for the AM2.5 estimates generally show greater bias than ERA-I/Land but smaller bias than CFSR and MERRA-Land.

The differences between MERRA-Land and ERA-I/ Land with PGF/VIC precipitation are reasonably less than AM2.5 and PGF/VIC since MERRA-Land and ERA-I/Land precipitation were bias corrected using gridded observations. Atmospheric modeling systems commonly involve errors in the intensity and the diurnal cycle of precipitation, which tends to come down as long-lasting "drizzle" (Dai 2006). Unsurprisingly, the AM2.5 and CFSR also suffer from such deficiencies. The drizzle rain leads to biased high precipitation for AM2.5 and CFSR. Much of this fine drizzle immediately evaporates from small-diameter droplets, leading to biased high ET. The AM2.5 precipitation rates are biased low in southern South America and biased high in the Amazon, central Africa, and South and Southeast Asia, likely due to the coarser resolution of the model compared to the spatial scale of convective systems in these tropical regions.
The runoff from MERRA-Land and CFSR are notably low, particularly in the tropical rain forest regions with dense vegetation cover. This may be due to the overestimated canopy interception parameters in their land surface models. Another remarkable feature of water fluxes from CFSR is extremely low runoff, which is consistent with previous studies (e.g., Yang et al. 2015). The drizzle component of the CFSR rainfall leads to immediate evaporation of the rainfall from droplets on the surface, and therefore not enough of the water can drip down through the canopy and generate runoff. Moreover, the underestimation of CFSR runoff is likely due to physical reasons related to the absence of lateral flow and subsurface hydrology in the land surface models used in CFSR. CFSR used the Noah land surface model to simulate the land surface process. The Noah model treated Earth as a uniform surface with no topography and no lateral flow. However, the lateral movement of surface and sustained subsurface saturation flow is an important source of total runoff. The second reason is related to subsurface hydrology. The model treated baseflow as a linear function of bottom-soil-layer drainage and assumes that the water table is shallow enough to be within the model soil layers (Schaake et al. 1996). However, the water table elevation varies dramatically depending on several factors. The model does not represent a water table response to storms where the lateral redistribution of flows contributes more to the total runoff, and likewise, does not treat capillary rise where upward water flow becomes an important process to charge soil moisture. Soil moisture-groundwater interactions and related runoff production have been included in the recent Noah multiparameterization model (Noah-MP; Niu et al. 2011) and have demonstrated a dramatic improvement for the hydrologic simulation results (Barlage et al. 2013). These features have not been incorporated into CFSR yet.

Figure 3 shows the PCF/VIC water budget absolute values and the differences of the water budget of the AM2.5 and three reanalysis datasets from the PGF/VIC baseline averaged across the longitudes from December to February (DJF), from June to August (JJA), and the complete period of record. Note that the PGF/VIC precipitation is based on the gridded observational CRU data product. In the Northern Hemisphere above $20^{\circ} \mathrm{N}$, the maximum bias of the AM2.5 precipitation is approximately $0.5 \mathrm{~mm}$ day $^{-1}$, which is mostly greater than the bias of MERRA-Land (maximum bias: $\sim-0.3 \mathrm{~mm} \mathrm{day}^{-1}$ ) and ERA-I/Land (maximum bias: $\sim 0.3 \mathrm{~mm} \mathrm{day}^{-1}$ ) but smaller than CFSR (maximum bias: $\sim 1 \mathrm{~mm} \mathrm{day}^{-1}$ ). In other regions, the AM2.5 simulation shows relatively large positive bias with the maximum value $\sim 2 \mathrm{~mm} \mathrm{day}^{-1}$ in the tropics and $\sim 4 \mathrm{~mm} \mathrm{day}^{-1}$ in the temperate zone of the Southern Hemisphere. These AM2.5 biases are generally greater 

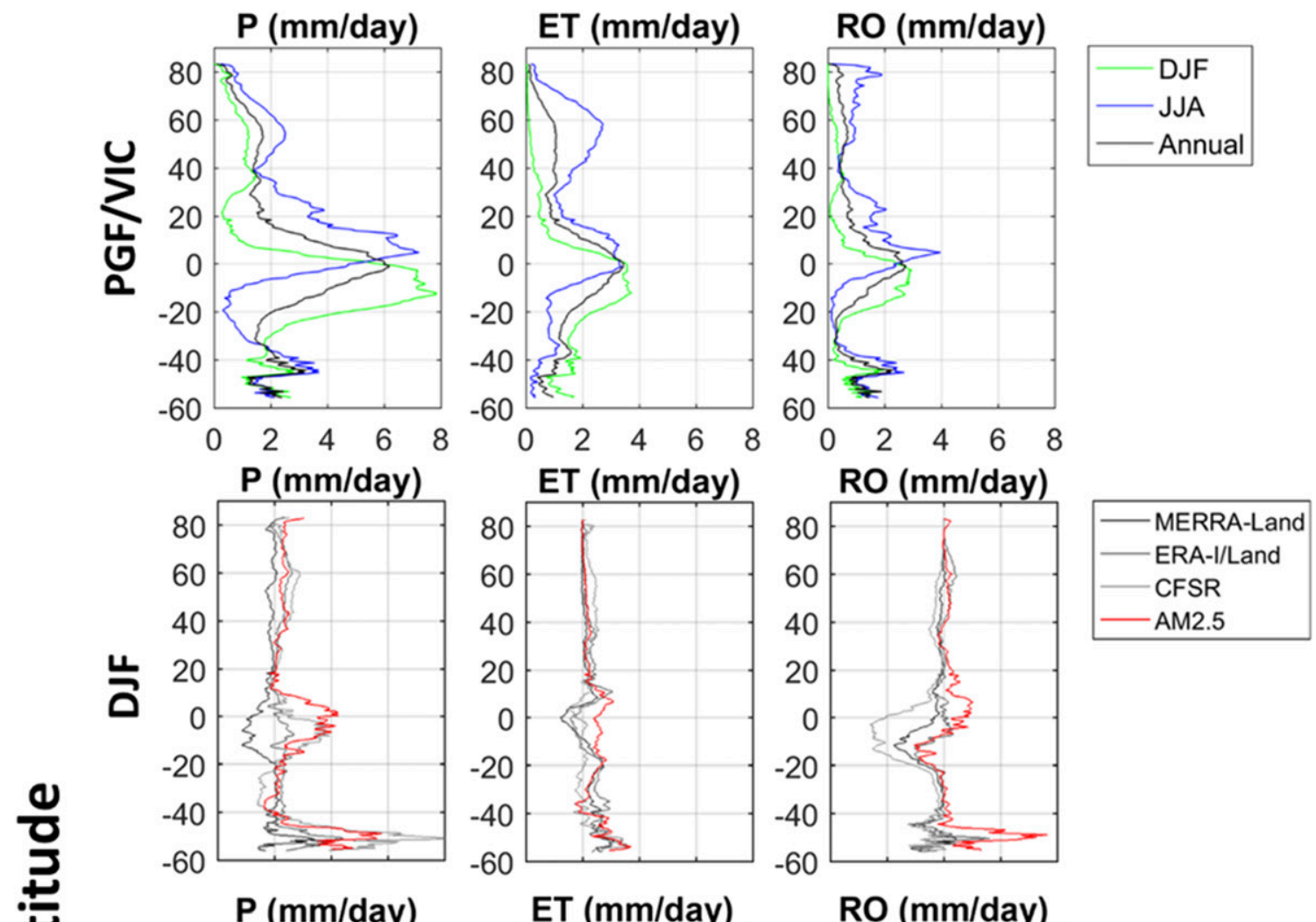

J


FIG. 3. The (first row) absolute values of PGF/VIC average water flux estimates across the latitude and the difference between each dataset and PGF/VIC for the long-term average water flux across the latitude and (second row) DJF, (third row) JJA, and (fourth row) all the years over 1991-2010. 
than most of the reanalyses except CFSR, which has a maximum bias of $\sim 5.5 \mathrm{~mm} \mathrm{day}^{-1}$ between $20^{\circ}$ and $60^{\circ} \mathrm{S}$. Like precipitation, the AM2.5 evapotranspiration bias is comparable to the differences of the three reanalyses except for a high bias over the tropics and northern and southern temperate zones. For runoff, the bias values of the AM2.5 simulations are greater than MERRA-Land and ERA-I/Land but lower than CFSR. There is a tendency to overestimate runoff near the tropics and midlatitudes in the Southern Hemisphere. There are large discrepancies between AM2.5 and the three reanalysis datasets in the tropics and midlatitudes of the Southern Hemisphere. The reason for the large runoff estimation uncertainty is likely due to the larger precipitation discrepancies among the models, the sensitivity to differences in subsurface parameterization and vegetation parameterization among the models, and the greatest uncertainty associated with the Global Runoff Data Centre (GRDC) runoff data in those sparsely observed regions. It is worth noting that the absolute magnitudes of the fluxes are the largest over tropical regions and the land fraction is small after $40^{\circ} \mathrm{S}$, which explains the notable biases of all the water budget estimates over tropics and the large noise over the temperate zone of the Southern Hemisphere.

\section{2) ENERGY FLUXES OVER LAND}

Figure 4 shows the global maps of PGF/VIC and the differences between each dataset and PGF/VIC for the long-term mean of net radiation, latent heat, and sensible heat over 1991-2010. The numbers in each of the maps are the global average differences in actual value and in percentage. With respect to the PGF/VIC, the AM2.5 net radiation has a global negative bias of only $\sim 1.42 \mathrm{~W} \mathrm{~m}^{-2}$ ( $\sim 2 \%$ of long-term mean net radiation). The global bias of latent heat is positive $\sim 7.8 \mathrm{~W} \mathrm{~m}^{-2}$ ( $\sim 22 \%$ of long-term mean latent heat). The global bias of sensible heat from the AM2.5 is negative $\sim 8.7 \mathrm{~W} \mathrm{~m}^{-2}$ ( $\sim 27 \%$ of long-term mean sensible heat). The performances of the AM2.5 energy budget components show several spatial differences between the three reanalyses, particularly for latent and sensible heat over sub-Saharan Africa, South America, and South and Southeast Asia. The long-term mean difference in net radiation between AM2.5 and PGF/VIC is smaller than the difference between the three reanalyses and the PGF/VIC globally. The larger net radiation errors in the reanalyses are likely due to the deficiencies in cloud parameterizations in the atmospheric component of the climate models found by previous studies (e.g., Zib et al. 2012). The AM2.5 latent heat shows more bias than CFSR, MERRA-Land, and ERA-I/Land. Its sensible heat shows negative bias, with the absolute value greater than ERA-I/Land and CFSR.
Figure 5 shows the PCF/VIC energy budget absolute values and the differences of the energy budgets of AM2.5 and three reanalyses from PGF/VIC, averaged across the longitudes for DJF, JJA, and the period of record. The incoming radiation (shortwave and longwave) in the PGF/VIC is based on the NASA SRB dataset, which is considered the best observational estimate available according to Raschke et al. (2006). The AM2.5 net radiation agreed well with the PGF/VIC dataset and the bias (with a maximum value $\sim 30 \mathrm{~W} \mathrm{~m}^{-2}$ ) was comparable to the differences of the three reanalyses with PGF/VIC. Land surface net radiation is mainly determined by absorption, reflectance, and emission of radiation by cloud and land cover (Bonan 2015). The AM2.5 bias in net radiation could be attributed to both cloud simulations in the atmospheric module and the land albedo modeling in the land module such as dynamics of snow and vegetation covers. Figure 4 also shows that the differences in energy budget variables are greater in the Southern Hemisphere during DJF than in the Northern Hemisphere and conversely smaller in the Southern Hemisphere during JJA than in the Northern Hemisphere, due to the changes of the net radiation magnitude. At $20^{\circ} \mathrm{N}$ in all seasons, the latent heat has the smallest differences compared to net radiation and sensible heat. Although the latent heat shows general agreement among the datasets for the Northern and Southern Hemisphere, visual inspection of the plots shows a positive bias in the AM2.5 as well as in the three reanalysis datasets. One factor affecting AM2.5 could be the parameterization of vegetation cover, which affects surface resistance and roughness length. It is also worth noting that the AM2.5 precipitation is higher than the PGF/VIC precipitation (Fig. 3), which likely causes a wet surface and potentially contributes to the positive bias in latent heat. Comparison of sensible heat from AM2.5, PGF/VIC, and three reanalyses is shown in Fig. 5. The AM2.5 sensible heat shows negative bias relative to PGF/VIC, which is likely attributed to the higher precipitation that produces higher latent heat and thus lowers sensible heat. In addition, the positive bias in the latent heat cancels out most of the negative bias in sensible heat, making the net radiation in AM2.5 relatively consistent with PGF/VIC.

\section{3) Summary of GLOBAl WATER AND ENERGY BUDGETS}

Table 1 summarizes global mean values of each surface water and energy budget variable from different datasets, global mean RMSE of each dataset relative to PGF/VIC, and pattern correlation of each dataset with PGF/VIC. For the global mean values, the AM2.5 and three reanalyses show consistently higher precipitation 

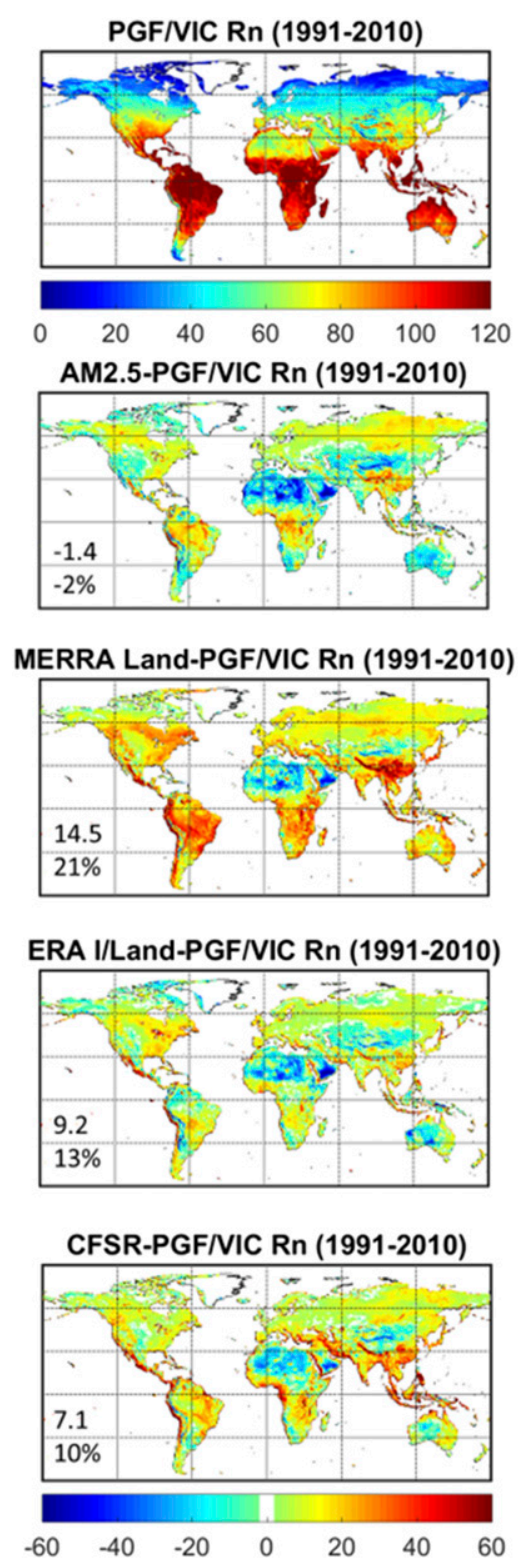

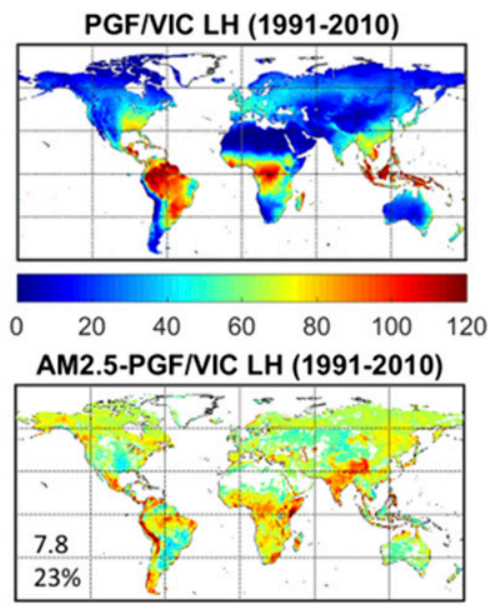

MERRA Land-PGF/NIC LH (1991-2010)



ERA I/Land-PGF/VIC LH (1991-2010)

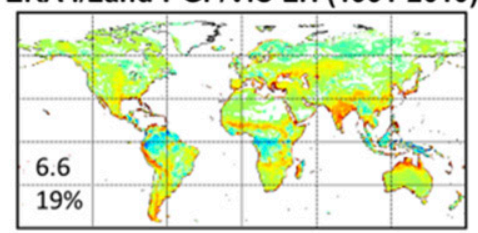

CFSR-PGF/VIC LH (1991-2010)

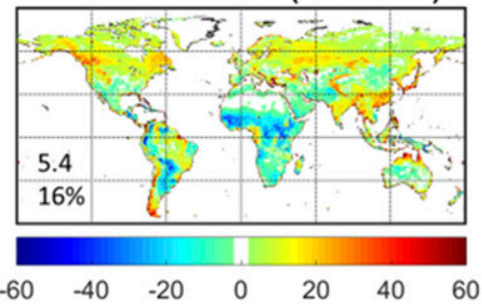

PGF/VIC SH (1991-2010)

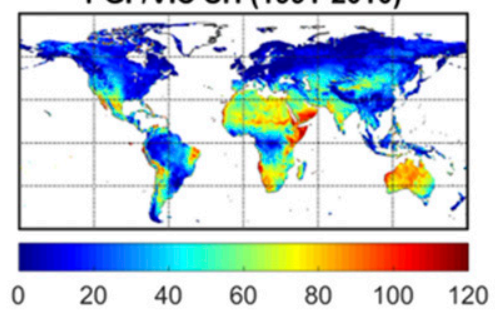

AM2.5-PGF/VIC SH (1991-2010)

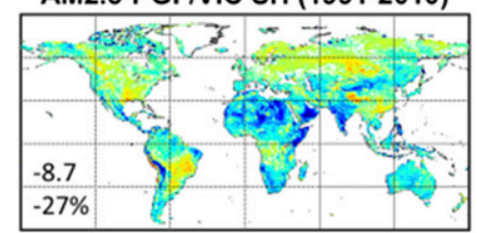

MERRA Land-PGF/VIC SH (1991-2010)



ERA I/Land-PGF/VIC SH (1991-2010)



CFSR-PGF/VIC SH (1991-2010)



FIG. 4. As in Fig. 2, but for long-term mean energy flux $\left(\mathrm{W} \mathrm{m}^{-2}\right)$.

and evapotranspiration than PGF/VIC. The AM2.5 generally overestimates water budget elements. The RMSE values of AM2.5 precipitation and evapotranspiration are smaller than CFSR but greater than MERRA-Land and ERA-I/Land; its runoff simulation has greater RMSE than all three reanalyses. For the energy budget, while the AM2.5 net radiation agreed very well with PGF/VIC, AM2.5 suffered from inappropriate partitioning of the net radiation, with the latent heat showing greater positive bias and sensible heat showing greater negative bias than the reanalyses. Besides the mean actual values over global land, Table 1 also shows the average RMSE of each dataset over all the grid points in global land, which reflects the average of the accuracy at different locations over the global land. For the water budget variables, AM2.5 mostly shows lower RMSE values than CFSR but higher RMSE values than MERRA-Land and ERA-I/Land. For the energy budget, AM2.5 shows relatively low RMSE values for net radiation and sensible heat but not for latent heat. In general, the result for the global mean RMSE shows different patterns with global mean values, suggesting substantial local to regional differences of the water and energy budget variables. 

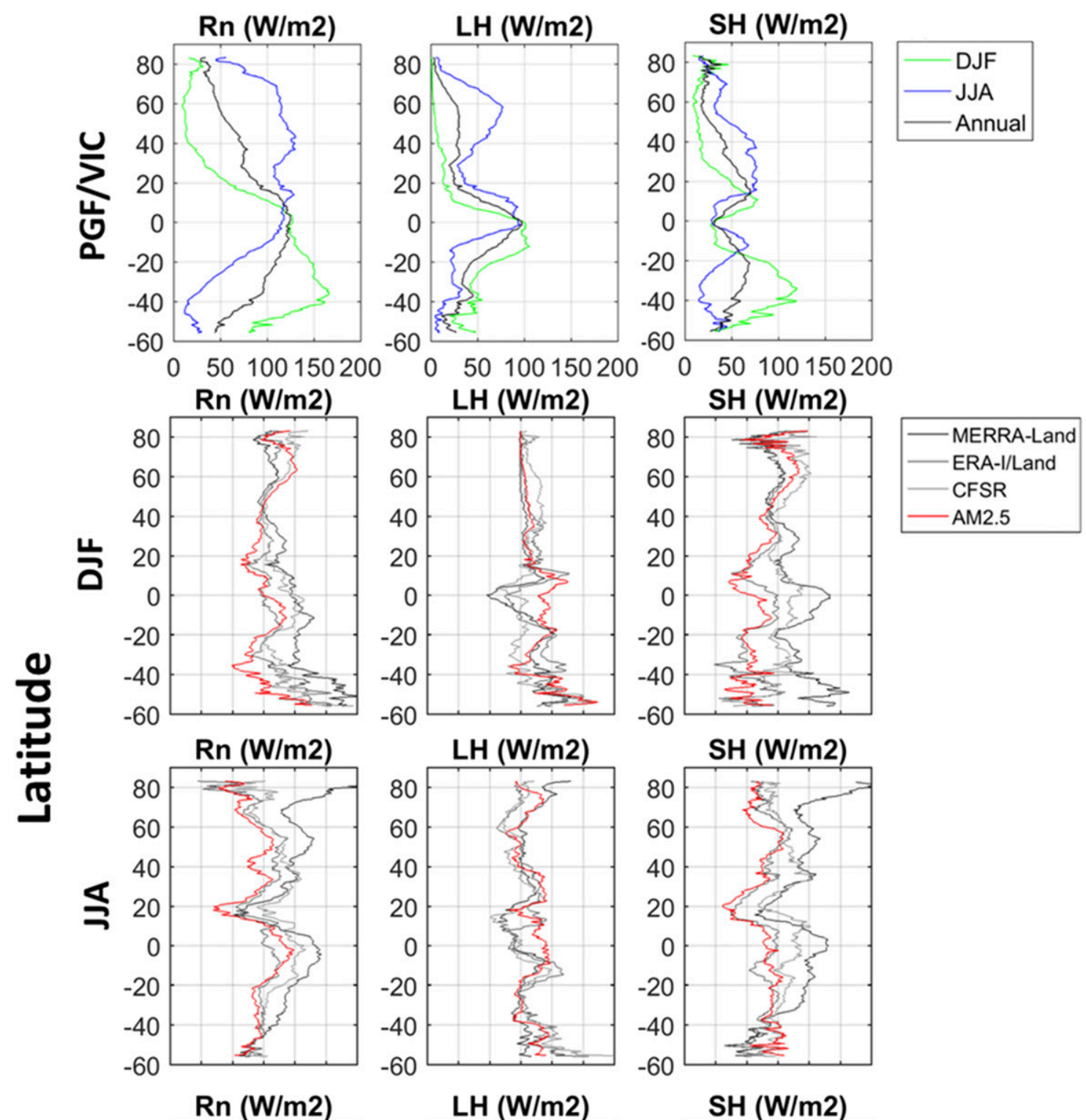

萡
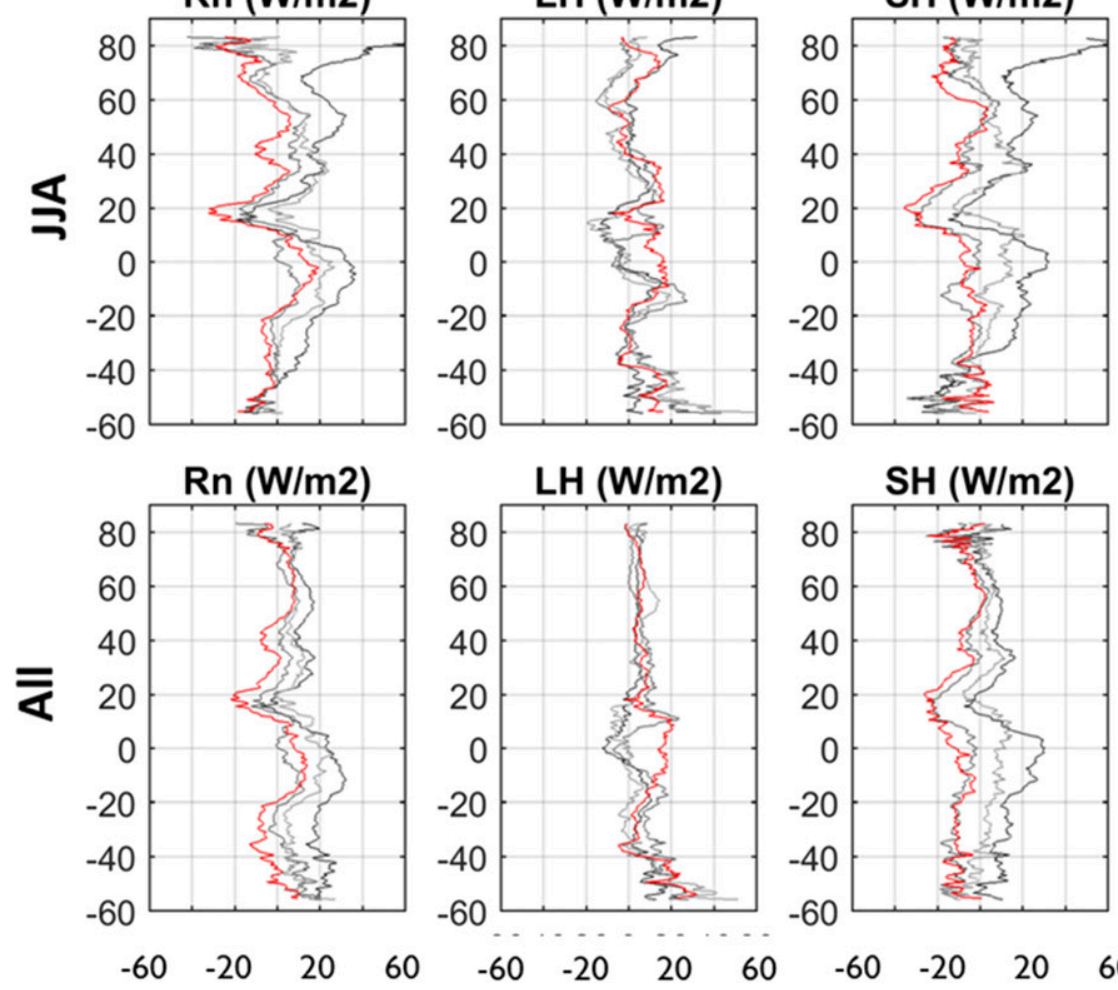

FIG. 5. As in Fig. 3, but for the long-term average energy flux. 
TABLE 1. Summary of long-term mean values of each dataset, global mean RMSE of each dataset relative to PGF/VIC, and pattern correlation of each dataset with PGF/VIC.

\begin{tabular}{|c|c|c|c|c|c|c|c|}
\hline \multirow[b]{2}{*}{ Metrics } & \multirow[b]{2}{*}{ Dataset } & $P$ & ET & RO & $\mathrm{Rn}$ & $\mathrm{LH}$ & $\mathrm{SH}$ \\
\hline & & \multicolumn{3}{|c|}{$\left(\mathrm{mm} \mathrm{day}^{-1}\right)$} & \multicolumn{3}{|c|}{$\left(\mathrm{W} \mathrm{m}^{-2}\right)$} \\
\hline \multirow{5}{*}{ Global mean values } & AM2.5 & 2.39 & 1.48 & 0.90 & 67.52 & 42.05 & 23.79 \\
\hline & PGF/VIC & 1.98 & 1.22 & 0.77 & 69.38 & 34.49 & 32.78 \\
\hline & MERRA-Land & 1.72 & 1.32 & 0.40 & 83.73 & 37.92 & 45.18 \\
\hline & ERA-I/Land & 2.19 & 1.41 & 0.74 & 78.56 & 41.07 & 33.50 \\
\hline & CFSR & 2.47 & 1.41 & 0.13 & 76.44 & 39.92 & 33.96 \\
\hline \multirow[t]{4}{*}{ Global mean RMSE } & AM2.5 & 1.13 & 0.60 & 0.76 & 18.20 & 17.17 & 22.66 \\
\hline & MERRA-Land & 0.71 & 0.53 & 0.55 & 21.86 & 15.28 & 25.14 \\
\hline & ERA-I/Land & 0.71 & 0.55 & 0.58 & 20.10 & 15.87 & 22.10 \\
\hline & CFSR & 1.22 & 0.66 & 0.60 & 19.90 & 18.66 & 24.23 \\
\hline \multirow{4}{*}{$\begin{array}{l}\text { Pattern correlation } \\
\quad \text { (nondimensional) }\end{array}$} & AM2.5 & 0.75 & 0.82 & 0.55 & 0.88 & 0.82 & 0.70 \\
\hline & MERRA-Land & 0.84 & 0.83 & 0.65 & 0.87 & 0.83 & 0.69 \\
\hline & ERA-I/Land & 0.87 & 0.77 & 0.62 & 0.87 & 0.77 & 0.61 \\
\hline & CFSR & 0.75 & 0.71 & 0.54 & 0.88 & 0.71 & 0.64 \\
\hline
\end{tabular}

The pattern correlations in Table 1 were calculated by averaging the pattern correlations for each month over the entire 1991-2010 period. It indicates the average similarity of the spatial patterns over time between each dataset and PGF/VIC. For the water budget variables, MERRA-Land and ERA-I/Land showed high pattern correlations, followed by AM2.5 and CFSR. The energy budget variables generally have greater pattern correlation values but smaller uncertainties than the water budget variables. The greater pattern correlation values and smaller uncertainties for energy budget variables are likely due to the strong latitudinal gradients of incident shortwave radiation and meridional temperature gradient compared to precipitation.

\section{b. Regional intercomparisons}

Figure 6 shows the differences in regional mean water fluxes between each dataset and PGF/VIC, grouped by botanical continent. Like the global results, the AM2.5 overestimates precipitation, evapotranspiration, and runoff over most of the regions, but with large spatial variations. The mean precipitation of the AM2.5 over many tropical regions (Central America, sub-Saharan Africa, and Asia-Tropical) showed a relatively high bias of more than approximately $1 \mathrm{~mm} \mathrm{day}^{-1}$. Over Alaska, the Amazon, Central America, and sub-Saharan Africa, AM2.5 evapotranspiration and runoff show relatively high bias of more than approximately $0.5 \mathrm{~mm} \mathrm{day}^{-1}$. For the water budget, the biases of AM2.5 are comparable to the differences of reanalyses with PGF/VIC in most of the regions. In only a few regions does AM2.5 show much higher bias than the three reanalyses, which includes Central America, sub-Saharan African, and Southeast Asia for precipitation and the Southeast Asia region for runoff. Figure 7 shows the differences in regional mean energy fluxes between each dataset and PGF/VIC, grouped by botanical continents. Like water budget elements, the biases of AM2.5 net radiation, latent heat, and sensible heat are mostly within the range of the difference between the three reanalyses with PGF/VIC in most of the regions. AM2.5 only shows higher bias than any reanalysis in the Saharan region for net radiation; in sub-Saharan Africa and Southeast Asia for latent heat; and in Alaska, the Mediterranean, South Africa, the Sahara, and South Asia for sensible heat. Overall, in terms of the regional actual mean bias, the AM2.5 shows relatively good performance representing land surface water and energy fluxes over different regions, and the biases are comparable to the differences of the reanalyses with PGF/VIC.

Figure 8 summarizes the comparison of anomaly correlations of monthly series of water and energy budget components between each dataset and PGF/VIC in different regions. While the AM2.5 bias relative to PGF/VIC is comparable to CFSR, MERRA-Land, and ERA-I/Land over many regions, in most instances, the anomaly correlations of the three reanalyses with PGF/ VIC are greater than AM2.5, suggesting that AM2.5 simulated actual values better than temporal variabilities. In particular, the anomaly correlations of AM2.5 precipitation and runoff are considerably lower than the three reanalyses. While the anomaly correlations of AM2.5 evapotranspiration and latent heat are significantly lower than the three reanalyses, their differences are not as remarkable as precipitation and runoff. The lower temporal anomaly correlations of AM2.5 are likely due to the ensemble mean of the AMIP members averaging out the intrinsic variability of the land surface fluxes. The variability that remains may be principally 
Difference in Actual Value ( $\mathrm{mm} /$ day)


FIG. 6. Difference between each dataset and PGF/VIC for the regional mean water flux over 1991-2010. Regions are grouped by botanical continents (see Table 2 for abbreviations).

just the SST-forced signal. As a result, the effect of the intrinsic internal variability of the atmosphere on land surface fluxes that is not forced by the SSTs, while captured in PGF/VIC and other reanalyses, is missing in the AM2.5 data. For the water budget variables, MERRALand and ERA-I/Land show relatively high correlations with PGF/VIC for both precipitation and runoff in most of the regions. On the other hand, MERRA-Land and ERA-I/Land show relatively lower correlations for the energy budget variables than for the water budget variables. This result indicates the correction of precipitation forcings and land surface model parameterizations improved the simulation of the water budget variables more than the energy budget variables. In Table 2, we
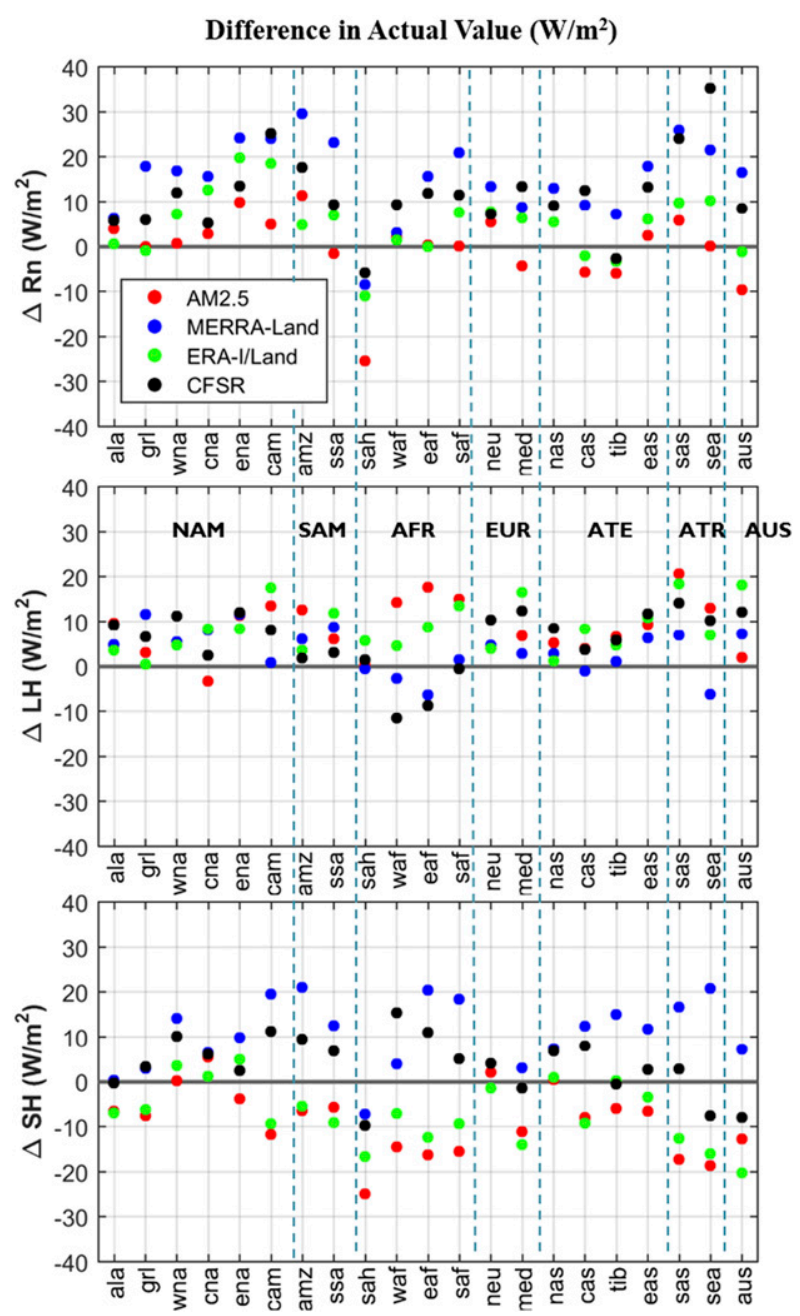

FIG. 7. As in Fig. 6, but for regional mean energy flux.

further examine the anomaly correlations of the AM2.5 with the PGF/VIC in each of the regions. The result shows that the anomaly correlations are the lowest in Greenland (GRL) and north Asia (NAS), likely due to the issues with land surface modeling of snow and albedo feedbacks to the atmosphere.

\section{Concluding remarks}

A primary goal of GEWEX is to improve coupled model predictions through the evaluation of climate models using regional-to-continental datasets. This study contributes to this goal by evaluating the surface water and energy budget variables from AM2.5 over land at regional-to-global scales against PGF/VIC as well as MERRA-Land, ERA-I/Land, and CFSR reanalysis datasets. This study also serves as an extension to the work by Tian et al. (2016), which assessed AM2.5 

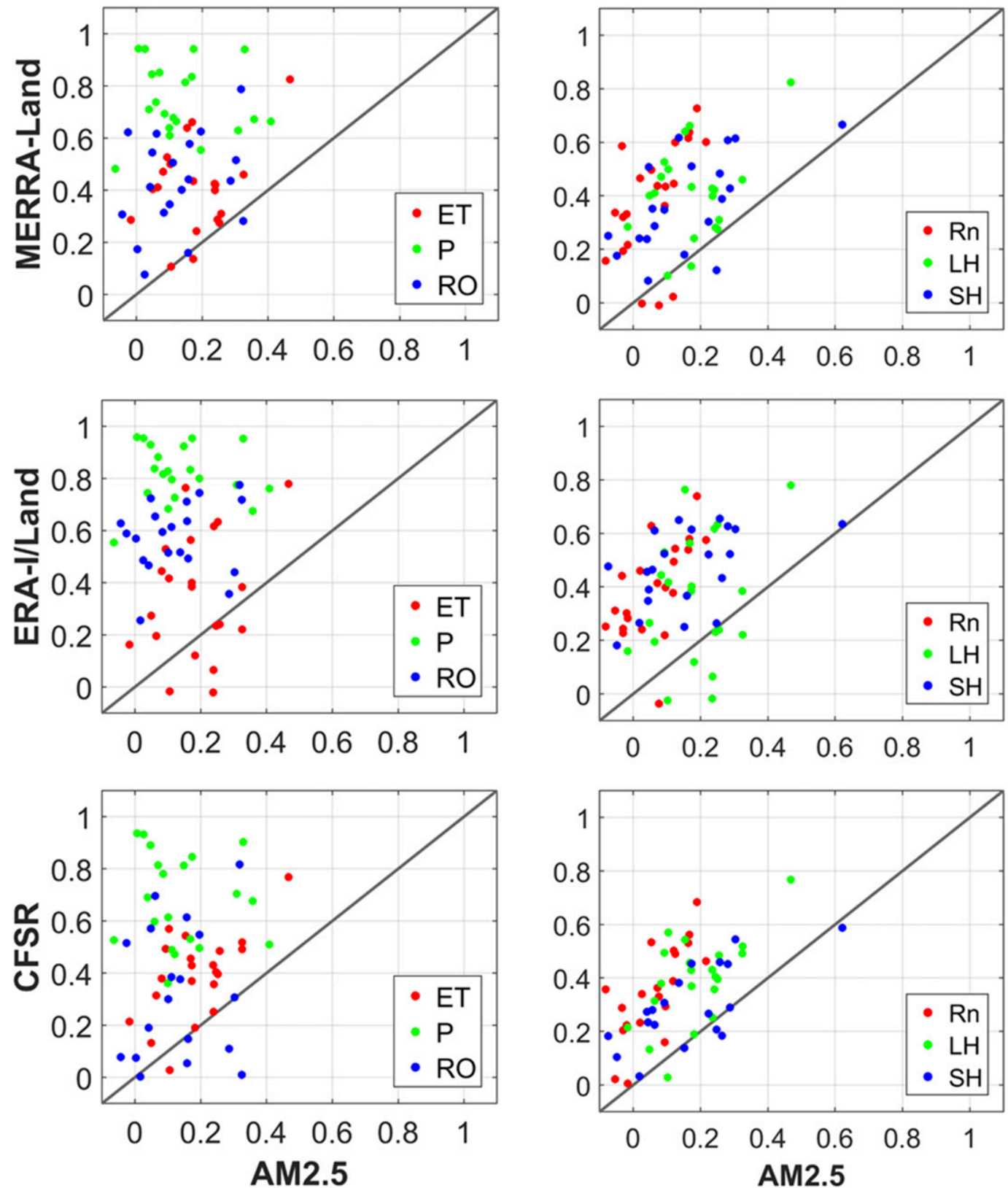

FIG. 8. Scatterplot of anomaly correlation between PGF/VIC and MERRA vs correlation between PGF/VIC and AM2.5, PGF/VIC and CFSR vs PGF/VIC and AM2.5, and PGF/VIC and ERA-Interim vs PGF/VIC and AM2.5. The point in the plot indicates correlations for monthly water (ET, $P$, and RO) and energy ( $\mathrm{Rn}, \mathrm{LH}$, and SH) series from 1991 to 2010 in each of the regions. The 1:1 line indicates that AM2.5 and reanalyses have the same similarity to PGF/VIC.

water and energy budgets over nine major African river basins. At the global scale, the AM2.5 precipitation, evapotranspiration, and runoff generally agreed well with the PGF/VIC as well as three reanalysis datasets except near the tropics. For the energy budget, while the AM2.5 net radiation agreed very well with the PGF/VIC (comparable to the three reanalyses), the AM2.5 improperly partitioned the net radiation, with latent heat showing positive bias and sensible heat showing negative bias. At the regional scale, the AM2.5 overestimated precipitation, evapotranspiration, and runoff in most of the regions, but with large variations between regions. The biases of the AM2.5 water budget components are comparable to the differences of MERRA-Land, ERA-I/Land, and CFSR 
TABLE 2. Anomaly correlations between AM2.5 and PGF/VIC in different regions, grouped by botanical continents: North America (NAM), South America (SAM), Africa (AFR), Europe (EUR), Asia-Temperate (ATE), Asia-Tropical (ATR), and Australasia (AUS). The regions are Alaska (ALA), Greenland (GRL), western North America (WNA), central North America (CNA), eastern North America (ENA), Central America (CAM), Amazon Basin (AMZ), southern South America (SSA), Sahara (SAH), Western Africa (WAF), Eastern Africa (EAF), Southern Africa (SAF), Northern Europe (NEU), Mediterranean Basin (MED), north Asia (NAS), central Asia (CAS), Tibet (TIB), east Asia (EAS), South Asia (SAS), and Southeast Asia (SEA). An asterisk denotes that the anomaly correlation is significant at the 0.05 level.

\begin{tabular}{|c|c|c|c|c|c|c|c|}
\hline \multirow[b]{2}{*}{ Continent } & \multirow[b]{2}{*}{ Region } & \multicolumn{6}{|c|}{ Water and energy budget variables } \\
\hline & & $P$ & ET & $\mathrm{RO}$ & $\mathrm{Rn}$ & LH & SH \\
\hline \multirow[t]{6}{*}{ NAM } & ALA & 0.04 & -0.02 & $0.16^{*}$ & 0.13 & -0.02 & $0.26 *$ \\
\hline & GRL & -0.06 & 0.11 & 0.02 & 0.07 & 0.10 & -0.05 \\
\hline & WNA & -0.18 & $0.17 *$ & 0.05 & $0.22 *$ & $0.17 *$ & 0.09 \\
\hline & CNA & $0.17 *$ & 0.08 & $0.20 *$ & 0.05 & 0.08 & $0.17 *$ \\
\hline & ENA & 0.05 & $0.25 *$ & 0.10 & $0.19 *$ & $0.24 *$ & 0.04 \\
\hline & CAM & $0.31 *$ & 0.10 & $0.14^{*}$ & -0.08 & 0.11 & $0.26^{*}$ \\
\hline \multirow[t]{2}{*}{ SAM } & AMZ & $0.41^{*}$ & $0.33 *$ & $0.29 *$ & 0.12 & $0.33^{*}$ & $0.29 *$ \\
\hline & SSA & $0.17^{*}$ & $0.26^{*}$ & 0.04 & 0.03 & $0.26^{*}$ & $0.14 *$ \\
\hline \multirow[t]{4}{*}{ AFR } & SAH & 0.09 & $0.15^{*}$ & $0.16^{*}$ & 0.10 & $0.15^{*}$ & $0.15^{*}$ \\
\hline & WAF & 0.10 & $0.17 *$ & 0.08 & 0.08 & $0.17 *$ & $0.16^{*}$ \\
\hline & EAF & $0.20^{*}$ & $0.25 *$ & $0.16^{*}$ & -0.05 & $0.25^{*}$ & 0.06 \\
\hline & SAF & 0.10 & 0.09 & -0.12 & -0.02 & 0.09 & $0.28 *$ \\
\hline \multirow[t]{2}{*}{ EUR } & NEU & 0.03 & $0.18 *$ & -0.02 & $0.17 *$ & $0.18^{*}$ & 0.04 \\
\hline & MED & 0.01 & 0.07 & 0.06 & 0.12 & 0.06 & $0.25 *$ \\
\hline \multirow[t]{4}{*}{ ATE } & NAS & 0.06 & 0.05 & 0.00 & -0.03 & 0.05 & 0.02 \\
\hline & CAS & $0.15^{*}$ & $0.24 *$ & $0.33^{*}$ & 0.02 & $0.24 *$ & $0.22 *$ \\
\hline & TIB & 0.12 & $0.17 *$ & 0.03 & -0.03 & $0.17 *$ & 0.05 \\
\hline & EAS & 0.07 & $0.24 *$ & 0.11 & $0.16^{*}$ & $0.24 *$ & 0.06 \\
\hline \multirow[t]{2}{*}{ ATR } & SAS & 0.11 & $0.33 *$ & -0.04 & -0.03 & $0.32 *$ & -0.07 \\
\hline & SEA & $0.36^{*}$ & $0.24 *$ & $0.30 *$ & 0.09 & $0.24 *$ & $0.62 *$ \\
\hline AUS & AUS & $0.33^{*}$ & $0.47 *$ & $0.32 *$ & -0.02 & $0.47 *$ & $0.30 *$ \\
\hline
\end{tabular}

with PGF/VIC in most regions. The regions with substantially higher bias include the regions near the tropics (Central America, sub-Saharan Africa, and Southeast Asia) for precipitation; sub-Saharan Africa, Amazon, and Asia-Tropical for evapotranspiration; and Southeast Asia for runoff. Similar to water budget components, the biases of the AM2.5 net radiation, latent heat, and sensible heat are generally comparable to the differences of MERRALand, ERA-I/Land, and CFSR with PGF/VIC. The AM2.5 only shows higher bias than any reanalysis in the Saharan region for net radiation; in sub-Saharan Africa and Southeast Asia for latent heat; and in Alaska, the Mediterranean, South Africa, the Sahara, and South Asia for sensible heat. While the biases of AM2.5 are comparable to the three reanalyses, in a number of instances, the temporal anomaly correlations of the three reanalysis datasets with PGF/VIC are greater than the AM2.5, suggesting that the AM2.5 represents the actual value better than the temporal variability. This is likely due to the ensemble mean of all the AM2.5 members averaging out the intrinsic variability of the land surface fluxes. Errors from the AM2.5 simulations for land surface water and energy fluxes are likely due to a combination of errors from drizzle rainfall effects of the atmospheric model, land surface simulations of dynamics of snow and vegetation cover, and coupled atmospheric-ocean simulations related to moisture advection from ocean to land. One of the notable errors in the AM2.5 simulation is its overestimated water budget variables near the tropics and temperate zone in the Southern Hemisphere. The high precipitation is most likely caused by the issues of coupled atmosphericocean simulations related to ocean evaporation and moisture transport from ocean to land near the tropics, which also induces high evapotranspiration and high runoff over land. The improper partitioning of land net radiation is due to the overestimation of latent heat and underestimation of sensible heat. The overestimation of latent heat is related to the positive bias of the land precipitation and evapotranspiration, which also leads to the underestimation of sensible heat. These biases will have significant impacts on the model's forecasting skill.

This work presents discrepancies in water and energy budget estimates among land surface hydrologic model simulations, observations, reanalysis, and highresolution climate model simulations. It demonstrates the challenge of estimating and evaluating land surface 
hydrologic fluxes at regional-to-global scales and highlights that continuing uncertainties in obtaining validated fluxes hinders model validation. The GEWEX LandFlux has been initiated to overcome this issue. It is an ongoing effort aimed at developing observation-based global land surface flux products (McCabe et al. 2016). The GEWEX LandFlux initiative products can be used with other satellite observations to facilitate objective model land surface flux evaluations in the future.

Acknowledgments. This work was supported in part by the NOAA Geophysical Fluid Dynamics Laboratory through the Princeton University Cooperative Institute for Climate Science (CICS), by the Auburn University Intramural Grants Program, and by the Alabama Agricultural Experimental Station (AAES) grant under the USDA National Institute of Food and Agriculture Hatch project Accession 1012578. The CFSR dataset was retrieved from the NOAA National Centers for Environmental Information at http://nomads.ncdc.noaa.gov/ data. The MERRA-Land dataset was obtained from the NASA/GES/DISC at http://disc.sci.gsfc.nasa.gov/daac-bin/ FTPSubset.pl. The ERA-Interim/Land was from the ECMWF at http://apps.ecmwf.int/datasets/data/interimland/. The PGF/VIC and AM2.5 simulation results and figures are available from the authors upon request (tiandi@auburn.edu). We thank the anonymous reviewers for the valuable comments and suggestions that helped improve the manuscript. We also thank Erin White from the U.S. Army Corps of Engineers for providing useful comments on the manuscript.

\section{REFERENCES}

Balsamo, G., and Coauthors, 2015: ERA-Interim/Land: A global land surface reanalysis data set. Hydrol. Earth Syst. Sci., 19, 389-407, https://doi.org/10.5194/hess-19-389-2015.

Barlage, M., M. Tewari, F. Chen, K. Manning, and G. MiguezMacho, 2013: North American regional climate simulations with WRF/Noah-MP validation and the effect of ground water interaction. Proc. 14th WRF User's Workshop, Boulder, CO, WRF, 40 pp., www2.mmm.ucar.edu/wrf/users/workshops/ WS2013/ppts/5B.2.pdf.

Betts, A. K., M. Köhler, and Y. Zhang, 2009: Comparison of river basin hydrometeorology in ERA-Interim and ERA-40 reanalyses with observations. J. Geophys. Res., 114, D02101, https://doi.org/ 10.1029/2008JD010761.

Bonan, G., 2015: Ecological Climatology: Concepts and Applications. Cambridge University Press, 563 pp.

Dai, A., 2006: Precipitation characteristics in eighteen coupled climate models. J. Climate, 19, 4605-4630, https://doi.org/ 10.1175/JCLI3884.1.

Dee, D. P., and Coauthors, 2011: The ERA-Interim reanalysis: Configuration and performance of the data assimilation system. Quart. J. Roy. Meteor. Soc., 137, 553-597, https://doi.org/ 10.1002/qj.828.
Delworth, T. L., and Coauthors, 2012: Simulated climate and climate change in the GFDL CM2.5 high-resolution coupled climate model. J. Climate, 25, 2755-2781, https://doi.org/ 10.1175/JCLI-D-11-00316.1.

Ek, M. B., K. E. Mitchell, Y. Lin, E. Rogers, P. Grunmann, V. Koren, G. Gayno, and J. D. Tarpley, 2003: Implementation of Noah land surface model advances in the National Centers for Environmental Prediction operational mesoscale Eta model. J. Geophys. Res., 108, 8851, https://doi.org/10.1029/ 2002JD003296.

Fernandes, K., R. Fu, and A. K. Betts, 2008: How well does the ERA40 surface water budget compare to observations in the Amazon River basin? J. Geophys. Res., 113, D11117, https:// doi.org/10.1029/2007JD009220.

Giorgi, F., and R. Francisco, 2000: Evaluating uncertainties in the prediction of regional climate change. Geophys. Res. Lett., 27, 1295-1298, https://doi.org/10.1029/1999GL011016.

Harris, I., P. D. Jones, T. J. Osborn, and D. H. Lister, 2014: Updated high-resolution grids of monthly climatic observationThe CRU TS3. 10 Dataset. Int. J. Climatol., 34, 623-642, https://doi.org/10.1002/joc.3711.

Jia, L., and Coauthors, 2015: Improved seasonal prediction of temperature and precipitation over land in a high-resolution GFDL climate model. J. Climate, 28, 2044-2062, https://doi.org/ 10.1175/JCLI-D-14-00112.1.

_ , and Coauthors, 2016: The roles of radiative forcing, sea surface temperatures, and atmospheric and land initial conditions in US summer warming episodes. J. Climate, 29, 4121-4135, https://doi.org/10.1175/JCLI-D-15-0471.1.

Koster, R. D., M. J. Suarez, A. Ducharne, M. Stieglitz, and P. Kumar, 2000: A catchment-based approach to modeling land surface processes in a general circulation model: 1 . Model structure. J. Geophys. Res., 105, 24 809-24 822, https://doi.org/ 10.1029/2000JD900327.

Materia, S., A. Borrelli, A. Bellucci, A. Alessandri, P. Di Pietro, P. Athanasiadis, A. Navarra, and S. Gualdi, 2014: Impact of atmosphere and land surface initial conditions on seasonal forecasts of global surface temperature. J. Climate, 27, 92539271, https://doi.org/10.1175/JCLI-D-14-00163.1.

McCabe, M. F., A. Ershadi, C. Jimenez, D. G. Miralles, D. Michel, and E. F. Wood, 2016: The GEWEX LandFlux project: Evaluation of model evaporation using tower-based and globally gridded forcing data. Geosci. Model Dev., 9, 283, https://doi.org/10.5194/gmd-9-283-2016.

Mitchell, T. D., and P. D. Jones, 2005: An improved method of constructing a database of monthly climate observations and associated high-resolution grids. Int. J. Climatol., 25, 693-712, https://doi.org/10.1002/joc.1181.

Niu, G. Y., and Coauthors, 2011: The community Noah land surface model with multiparameterization options (Noah-MP): 1. Model description and evaluation with local-scale measurements. J. Geophys. Res., 116, D12109, https://doi.org/ 10.1029/2010JD015139.

Pan, M., A. K. Sahoo, T. J. Troy, R. K. Vinukollu, J. Sheffield, and E. F. Wood, 2012: Multisource estimation of long-term terrestrial water budget for major global river basins. J. Climate, 25, 3191-3206, https://doi.org/10.1175/JCLI-D-11-00300.1.

Raschke, E., S. Bakan, and S. Kinne, 2006: An assessment of radiation budget data provided by the ISCCP and GEWEXSRB. Geophys. Res. Lett., 33, L07812, https://doi.org/10.1029/ 2005 GL025503.

Reichle, R. H., R. D. Koster, G. J. De Lannoy, B. A. Forman, Q. Liu, S. P. Mahanama, and A. Touré, 2011: Assessment and enhancement 
of MERRA land surface hydrology estimates. J. Climate, 24, 63226338, https://doi.org/10.1175/JCLI-D-10-05033.1.

Rienecker, M. M., and Coauthors, 2008: The GEOS-5 Data Assimilation System-Documentation of Versions 5.0.1, 5.1.0, and 5.2.0. NASA Tech. Memo. NASA/TM-2008-104606, Vol. 27, 97 pp., https://gmao.gsfc.nasa.gov/pubs/docs/Rienecker369.pdf.

— rospective Analysis for Research and Applications. J. Climate, 24, 3624-3648, https://doi.org/10.1175/JCLI-D-11-00015.1.

Saha, S., and Coauthors, 2010: The NCEP Climate Forecast System Reanalysis. Bull. Amer. Meteor. Soc., 91, 1015, https://doi.org/ 10.1175/2010BAMS3001.1.

Schaake, J. C., V. I. Koren, Q.-Y. Duan, K. Mitchell, and F. Chen, 1996: Simple water balance model for estimating runoff at different spatial and temporal scales. J. Geophys. Res., 101, 7461-7475, https://doi.org/10.1029/95JD02892.

Sheffield, J., and E. F. Wood, 2007: Characteristics of global and regional drought, 1950-2000: Analysis of soil moisture data from off-line simulation of the terrestrial hydrologic cycle. J. Geophys. Res., 112, D17115, https://doi.org/10.1029/2006JD008288.

_ G. G. Goteti, and E. F. Wood, 2006: Development of a 50-year high-resolution global dataset of meteorological forcings for land surface modeling. J. Climate, 19, 3088-3111, https://oi.org/ 10.1175/JCLI3790.1.

— , K. M. Andreadis, E. F. Wood, and D. P. Lettenmaier, 2009: Global and continental drought in the second half of the twentieth century: Severity-area-duration analysis and temporal variability of large-scale events. J. Climate, 22, 1962 1981, https://doi.org/10.1175/2008JCLI2722.1.

Szeto, K. K., 2007: Assessing water and energy budgets for the Saskatchewan River Basin. J. Meteor. Soc. Japan, 85A, 167-186, https://www.jstage.jst.go.jp/article/jmsj/85A/0/85A_0_167/_pdf.
Tian, D., M. Pan, L. Jia, G. Vecchi, and E. F. Wood, 2016: Assessing GFDL high-resolution climate model water and energy budgets from AMIP simulations over Africa. J. Geophys. Res. Atmos., 121, 8444-8459, https://doi.org/ 10.1002/2016JD025068.

Troy, T. J., E. F. Wood, and J. Sheffield, 2008: An efficient calibration method for continental-scale land surface modeling. Water Resour. Res., 44, W09411, https://doi.org/10.1029/ 2007WR006513.

Vinukollu, R. K., J. Sheffield, E. F. Wood, M. G. Bosilovich, and D. Mocko, 2012: Multimodel analysis of energy and water fluxes: Intercomparisons between operational analyses, a land surface model, and remote sensing. J. Hydrometeor., 13, 3-26, https://doi.org/10.1175/2011JHM1372.1.

Xie, P., and P. A. Arkin, 1997: Global precipitation: A 17-year monthly analysis based on gauge observations, satellite estimates, and numerical model outputs. Bull. Amer. Meteor. Soc., 78, 2539, https://doi.org/10.1175/1520-0477(1997)078<2539: GPAYMA $>2.0 . \mathrm{CO} ; 2$.

—, M. Chen, and W. Shi, 2010: CPC unified gauge-based analysis of global daily precipitation. 24th Conf. on Hydrology, Atlanta, GA, Amer. Meteor. Soc., 2.3A, https://ams.confex. com/ams/90annual/techprogram/paper_163676.htm.

Yang, R., M. Ek, and J. Meng, 2015: Surface water and energy budgets for the Mississippi River basin in three NCEP reanalyses. J. Hydrometeor., 16, 857-873, https://doi.org/10.1175/ JHM-D-14-0056.1.

Zib, B. J., X. Dong, B. Xi, and A. Kennedy, 2012: Evaluation and intercomparison of cloud fraction and radiative fluxes in recent reanalyses over the Arctic using BSRN surface observations. J. Climate, 25, 2291-2305, https://doi.org/10.1175/ JCLI-D-11-00147.1. 